\title{
Integrando ecologia, economia e geotecnologia em tomadas de decisão
}

\author{
Integrating ecology, economy and geotechnology in decision making
}

\section{L'intégration des l'écologie, l'économie, la géotechnique et le processus décisionnel}

La integración de la ecología, la economía y geotecnología en la toma de decisiones

\author{
Andrea Santos Garcia* \\ (deiagarciaa@gmail.com) \\ Luiz Carlos Acorci Filho** \\ (luiz_acorci@hotmail.com) \\ Sergio Desimone Garcia*** \\ (hydral@ibest.com.br)
}

Recebido em 10/12/2012; revisado e aprovado em 27/04/2013; aceito em 10/07/2013

\begin{abstract}
Resumo: Este estudo objetivou caracterizar uma Área de Preservação Permanente baseando-se nos princípios da sustentabilidade. Para tal, foram aplicadas técnicas de geotecnologia, assim como conceitos ambientais, econômicos e sociais. Os métodos aqui utilizados podem ser transferidos para outras áreas de estudo e facilitar tomadas de decisões. Palavras-chave: APA Guariroba. Serviços ecossistêmicos. Custo-benefício.
\end{abstract}

Abstract: This study aimed characterize an Area of Permanent Preservation based on sustainability context. To such purposes it was applied geotechnology techniques, as environmental, economic and social concepts. The methods employed to carry out this study can be transfer to other study areas and make decision process easier.

Key words: APA Guariroba. Ecosystems services. Cost-benefit.

Resummé: Cette étude a pour objectif de cibler et définir une Aire de Conservation Permanente par rapport à son développement durable. Pour ces fins, il a été appliqué techniques géotechnique, et les environnemental, économiques et sociaux concepts. Les méthodes utilisées mener à bien cette étude peuvent être transférées à d'autres site d'étude et de rendre le processus de décision plus facile.

Mots-clés: APA Guariroba. Services écosystémiques. Coûts-bénéfices.

Resumen: Esta investigación tuvo como objetivo evaluar un Área de Preservación Permanente, tomando como base los principios de la sustentabilidad. Para tal, se aplicaron técnicas de geotecnologia, y conceptos ambientales, económicos y sociales. La metodología utilizada en este estudio puede ser transferido y servir como base para tomar decisiones más racionales.

Palabras clave: APA Guariroba. Servicios ecosistémicos. Costo-beneficio.

\section{Introdução}

A produção agropastoril é responsável por uma grande parcela do PIB brasileiro, cerca de R $\$ 192$ bilhões em 2011 (IBGE, 2012). Comumente o desenvolvimento desse setor e a conservação do meio ambiente são colocados em posições antagônicas. Um exemplo foi a extensa discussão sobre o Código Florestal brasileiro, a qual era dividida entre bancadas ruralistas e conservacionistas defendendo diferentes interesses (METZGER et al., 2010; SBPC, 2011; SPAROVEK et al., 2011; STOKSTAD, 2011; TOLLEFSON, 2011; NAZARENO, 2012).

Contudo o meio ambiente é fonte de diversos serviços ambientais responsáveis por suportar a produção agropastoril maciça e a subsistência em geral. São exemplos disso o fornecimento de água bruta, manutenção temperatura e umidade, polinização, matérias primas diversas, entre outros (COSTANZA et al., 1997). Esses serviços são produtos naturais gerados na interação da biota entre si e entre o meio em que estão. Essas interações são complexas, principalmente nos trópicos, onde a biodiversidade e energia são maiores (CHIARAVALLOTI; VALLADARES-PÁDUA, 2011).

A procura por equilíbrio entre a produção/deposição e manutenção do meio ambiente gerou o termo "Desenvolvimento Sustentável" em 1983, no Relatório Brundtland. Desde então, organizações ao

\footnotetext{
* Universidade de São Paulo (USP), Piracicaba, São Paulo, Brasil.

** Projeto Isca Viva, Campo Grande, MS, Brasil.

*** Hydral Comercial Técnica Ltda., Campo Grande, MS, Brasil.
} 
redor do mundo, de pequenas entidades ao Banco Mundial, adotaram o conceito "Sustentabilidade" para marcar uma nova filosofia de desenvolvimento. A sustentabilidade leva em consideração o desenvolvimento social, econômico e ambiental em longo prazo. Para ser sustentável, a atividade deve ser economicamente eficiente, socialmente includente e ecologicamente equilibrada (GOODLAND, 1995).

O planejamento deve ser a base para a tomada de decisão quando o objetivo é a eficiência de desenvolvimento socioeconômico. Apesar de ser o alicerce para uma decisão de cunho sustentável, esse conceito não vem, necessariamente, sendo ligado à esfera ambiental (DELALIBERA et al., 2008).

Uma base fundamental para o planejamento é o conhecimento territorial aliado às hipóteses de situações futuras. A degradação ambiental está diretamente ligada aos interesses políticos e econômicos que determinam e orientam a ocupação do território. Assim, a sustentabilidade de uma área é ligada ao contexto social, econômico e ambiental e deve ser vista pelo aspecto espacial e temporal. $\mathrm{O}$ avanço das tecnologias de sensoriamento remoto tem facilitado o planejamento e gerenciamento dessas informações. Essas tecnologias conferem certa facilidade, rapidez e razoável precisão na comparação de cenários (PARANHOS FILHO et al., 2008).

Um tomador de decisão, ou stakeholder, precisa organizar a sua gama de opções de acordo com os benefícios e custos econômicos, sociais e ambientais que cada um pode trazer. A análise pode ser apresentada em distintas perspectivas (do usuário, da eficiência, fiscal, distributiva ou ecológica), cada uma delas revelando os perdedores e os beneficiários, e as preferências do stakeholder. A partir de um ordenamento, as comparações entre situações futuras se tornam mais racionais (MORAES, 2008).

O principal objetivo deste estudo foi analisar a evolução da paisagem na Área de Preservação Ambiental Guariroba e seus efeitos ecológicos, econômicos e sociais. Dessa maneira, foi elaborado um método de análise lógico, de baixo custo e fácil replicação. Este estudo pode auxiliar nas tomadas de decisões para outras áreas além da APA Guariroba.

\section{Materiais e métodos}

\section{Área de estudo}

A APA Guariroba está situada integralmente no município de Campo Grande, Mato Grosso do Sul, a sudeste do perímetro urbano e cerca de $35 \mathrm{~km}$ do centro da cidade (Figura 1). Com área total aproximada de 36.190 hectares, foi instituída pelo Poder Público Municipal através do Decreto n. 7.183, de 21 de setembro de 1995. A APA Guariroba teve sua criação vinculada à necessidade de recuperação e conservação do principal sistema produtor de água bruta para abastecimento público de Campo Grande. A paisagem da APA é caracterizada por formações de Cerrado. As fitofisionomias que mais se destacam são cerradão, cerrado denso e áreas úmidas. Campo/pastagem é a formação mais representativa, sendo encontrado também florestas plantadas (eucalipto) e atividades de aquicultura. As características da área aqui citadas são encontradas no Plano de Manejo APA do Guariroba (CAMPO GRANDE, 2007).

O clima predominante na região, conforme a classificação de Köppen é do tipo Aw. Este é definido como Clima quente e úmido com chuvas de verão, tendo como característica a ocorrência de 4 a 5 meses secos e temperatura do mês mais frio superior a $18^{\circ} \mathrm{C}$. O período entre outubro e março configura a estação úmida local, sendo entre novembro e janeiro os meses mais chuvosos. Já o período considerado mais seco é entre junho e agosto, quando as taxas são habitualmente inferiores a $50 \mathrm{~mm}$.

A APA Guariroba é dominada por sucessão de Neossolo Quartzarênico (Areia Quartzosa). Restrito a porção inferior das vertentes (em associação a áreas de ocorrência de basaltos), é encontrado Latossolo Vermelho (típico ou distroférrico), de textura média a muito argilosa.

Os solos da APA apresentam forte limitação ao uso agrícola intensivo, devido principalmente às extensas e contínuas áreas muito arenosas. Solos arenosos, em um perfil com espessura de 2 metros, apresentam baixa capacidade de retenção de água (em torno de $100 \mathrm{~mm}$ de água disponível). Outro fator limitante é o caráter distrófico do solo, isto é, são solos quimicamente pobres, que exigem, para sua utilização, uma fertilização intensiva, corretiva e de manutenção. 


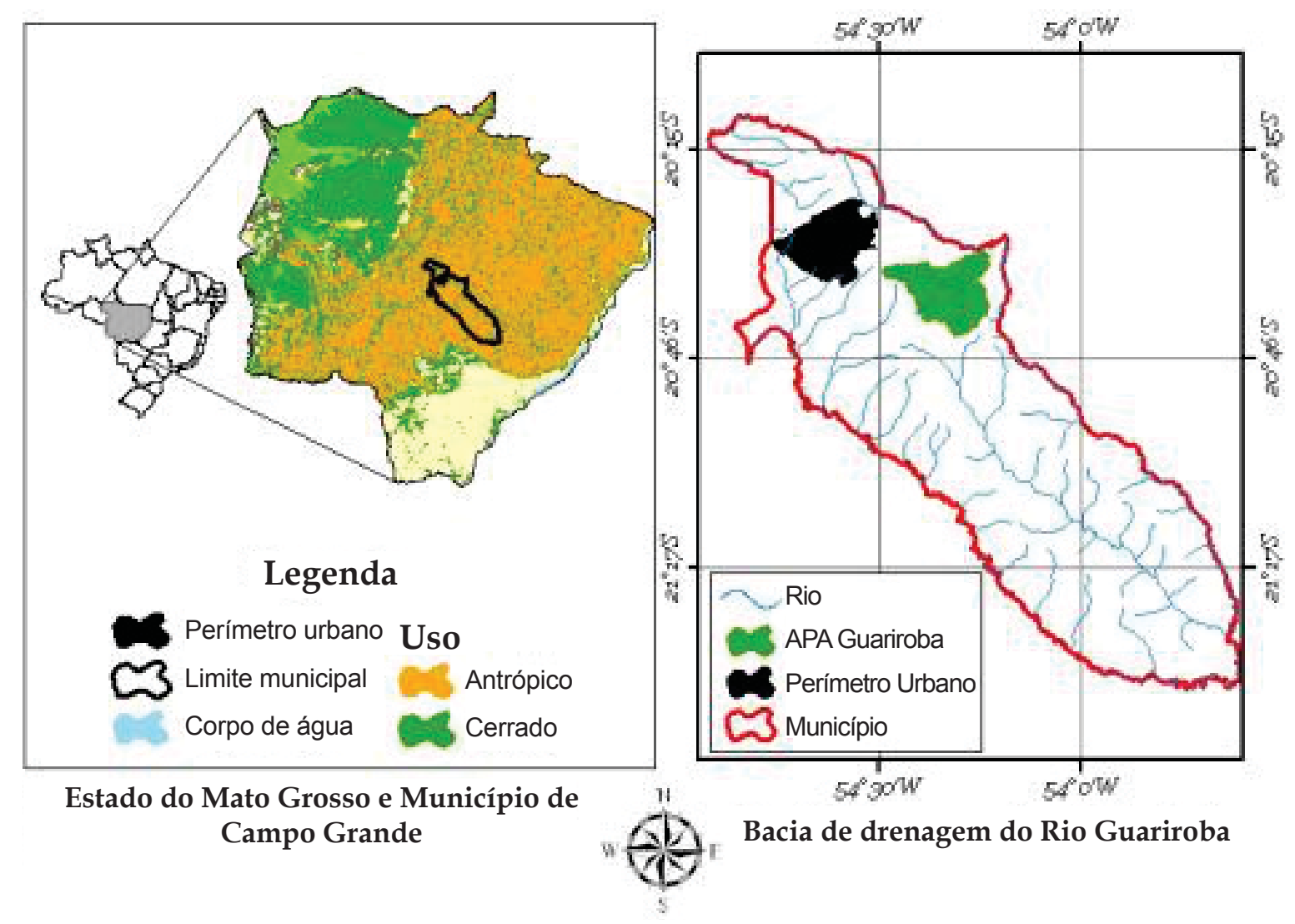

Figura 1 -'Localização da área de estudo

\section{Análise ambiental}

Para caracterizar e avaliar a ocupação da paisagem estudada, foram utilizadas ferramentas de geoprocessamento as quais possibilitam comparações da paisagem entre períodos distintos. Para tal, foram utilizadas imagens de satélite Landsat-5, sensor TM (Thematic Mapper), dos anos de 1984 e 2011 na composição RGB 432.

As imagens foram georreferenciadas e as áreas de interesse recortadas com o auxílio do software ArcGis. A base de corte (shapes) utilizada e todos os dados de relevo e cobertura de solo foram fornecidos pela Prefeitura Municipal de Campo Grande.

A classificação do uso de solo foi feita no software Multispec, o qual é disponibilizado gratuitamente. O tipo de classificação utilizada foi a supervisionada. Esse tipo de classificação é baseado em algoritmos que reconhecem padrões espectrais na imagem. $O$ analista fornece amostras na área de treinamento (treinador), a partir das quais são determinados valores e variabilidade para cada banda e classe.

Nesse estudo foi utilizado o algoritmo Extraction and Classification of Homogeneous Objects (ECHO) classifier. Esse algoritmo combina características espectrais e espaciais/ texturais. Para avaliar o mapeamento temático estatisticamente, utilizamos o coeficiente kappa extraído da matriz de erro (LU et al., 2004).

A legenda adotada inclui as seguintes classes de uso e cobertura do solo: cerrado florestado, mata ciliar, silvicultura, pastagem, pastagem em degradação, pastagem degradada, solo exposto, corpos d'água e nuvens (Figura 2). Os mapas de uso e cobertura resultantes passaram por inspeção visual e comparação com as composições coloridas. 


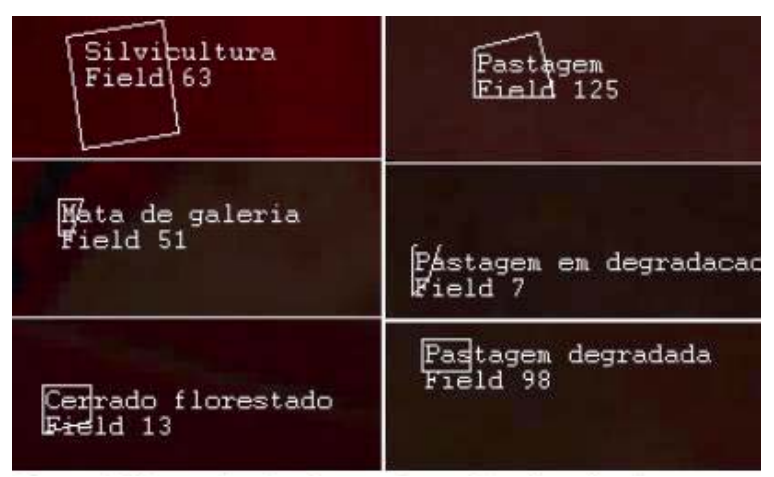

Figura 2 - Exemplos de classes de uso do solo adotadas

\section{Análises econômicas}

$\mathrm{Na}$ análise de custo-benefício (ACB) normalmente se consideram duas óticas: a financeira ou privada e a econômica ou social. Sob a ótica privada, a análise de custobenefício busca maximizar os lucros, com base nos preços de mercado. Do ponto de vista da sociedade, a eficiência de um projeto, ação ou política deve considerar outros elementos (os efeitos externos gerados pelo projeto ou política, sejam eles negativos ou positivos), e os preços de mercado são corrigidos de todas as distorções que alteram seu valor real (MORAES, 2008). Portanto um projeto ou política é aceito se:

[B-C] $>0$ onde,

$\mathrm{B}=$ benefícios do projeto ou política (incluindo benefícios ambientais), e $\mathrm{C}=$ custos do projeto ou política (incluindo custos ambientais).

Para comparar os usos de solo (naturais e antrópicos) na ACB foi calculado o valor de cada hectare baseado na lucratividade de cada atividade. O parâmetro social foi baseado em um comparativo entre empregos oferecidos diretamente, enquanto os ambientais, no nível de perturbação causada dentro da área de estudo.

Para evitar shadow prices e mascarar valores de custos e benefícios calculados para cada item optou-se obter os valores diretamente com técnicos agrônomos e proprietários rurais com atividades em desenvolvimento na área de estudo (HESS et al., 1980). O Sistema de Produção oferecido pela EMBRAPA foi usado para certificar as proporções entre os valores obtidos (http:/ / sistemasdeproducao.cnptia.embrapa.br/).
Com base nas entrevistas foi elaborada uma tabela com as atividades desenvolvidas no local e seus valores de (1) Custo, (2) Receita bruta, (3) Índice de lucratividade, (4) Risco de investimento, (5) Tempo de retorno médio (Payback), (6) empregos gerados diretamente e (7) Impacto ambiental. É importante destacar que o quadro foi elaborado para um hectare de área produtiva para facilitar a comparação entre atividades.

Os valores dos ecossistemas naturais são baseados na mensuração de valores monetários utilizados na valoração de serviços ambientais fornecidos por essas áreas. Valores de serviços ecossistêmicos podem ser definidos como o valor total dos serviços e produtos ecossistêmicos providos por diferentes tipos de ecossistemas (MARTINEZ et al., 2009).

Segundo Costanza et al. (1997), há muitas maneiras de se valorar serviços ambientais, tanto direta como indiretamente. Os mais comuns são aqueles que estimam um valor que a sociedade está disposta a pagar, que calcula o valor marginal dos serviços e os que transferem valores. Cada um deles possui seus prós e contras, e, apesar dos avanços nessa área de estudo, ainda há muitas incertezas e confusões.

Boyd e Banzhaf (2006) sugerem uma unificação dos conceitos e métodos relacionados à valoração dos serviços ambientais $\mathrm{e}$ apresentam outra definição: serviços ambientais são componentes da natureza, diretamente aproveitáveis, consumidos ou usados para produzir bem-estar para a população. Em outras palavras, são serviços finais da natureza.

Para estimar os valores dos serviços ambientais da APA Guariroba, como sugerido por Boyd e Banzhaf (2006), foi utilizado um serviço final - produção de água bruta. É importante salientar que esse estudo tem o objetivo de fornecer um valor mínimo para comparação.

O cálculo foi baseado no volume de água captado pela empresa concessionária Águas Guariroba em 2007, cerca de 38.833.080 $\mathrm{m}^{3}$ (CAMPO GRANDE, 2007), e a tarifa Social de consumo (o menor valor entre as tarifas), $\mathrm{R} \$ 1,22 / \mathrm{m}^{3}$ (CAMPO GRANDE, 2011). A partir dessas duas variáveis, foram descontados $80 \%$ do valor monetário total - relativo a custos, como recomenda De Groot et al. (2002).

A área de estudo possui diferentes formações naturais e antropizadas com 
diferentes pesos na produção de água, os quais necessitam ser embutidos no cálculo do valor dessas áreas. Como estudos realizados no Cerrado ou Savanas são raros, foram utilizado dois trabalhos realizado por Costanza para ponderar sobre esses pesos - uma revisão mundial (COSTANZA et al., 1997) e um trabalho muito detalhado para o estado de New Jersey/EUA (COSTANZA et al., 2006). Os trabalhos foram adaptados para a realidade da APA Guariroba em quatro passos: (1) somaram-se os valores obtidos por Costanza et al. (2006) para as classes que eram encontradas na APA ("Floresta", "Mata ciliar", "Áreas úmidas", e "Cursos de água") obtendo-se um total. Segundo Costanza et al. (1997), pastagens ou solo exposto não contribuem na produção de água, logo essas classes de cobertura de solo não entraram no cálculo;

(2) foi calculado o valor de importância (porcentagem) para cada uma das classes "Floresta”, "Mata ciliar", “'Áreas úmidas", e "Cursos de água" a partir dos valores parciais e totais apresentados pelos autores;

(2) dividiu-se o valor monetário arrecadado pela empresa concessionária com a captação de água por cada valor de importância, obtendo-se o valor monetário de cada classe ("Floresta", "Mata ciliar", "Áreas úmidas", e "Cursos de água");

(3) como na classificação realizada não foi feita a diferenciação entre "Mata ciliar" e "Área úmida", a área de "Mata ciliar" foi divida em duas - observações de campo suportam essa estratégia;

(4) com esses valores mais os valores de áreas obtidos para 1984 e 2011, foram calculados os valores monetários por hectare para diferentes coberturas de solo.

\section{Resultados e discussão}

A classificação automática supervisionada foi uma ferramenta que apresentou bons resultados para avaliar o uso de solo. Foi possível diferenciar várias classes de uso, inclusive classes bem semelhantes como formações florestais. O índice Kappa para ambos os anos foram altos, em torno de $94 \%$ e $98 \%$, e suas variâncias baixas, comprovando a eficiência do método utilizado (Tabela 1 e 2).

Tabela 1 - Acurácia referente à homogeneidade das amostras e a confiança da classificação da imagem de 1984.

\begin{tabular}{|l|c|c|}
\hline Acurácia & $\begin{array}{c}\text { Referência } \\
(\mathbf{\%})\end{array}$ & $\begin{array}{c}\text { Confiança } \\
(\mathbf{\%})\end{array}$ \\
\hline Cerrado florestado & 91,8 & 88,8 \\
\hline Mata de galeria & 87,1 & 90 \\
\hline Curso de água & 81,8 & 100 \\
\hline Pastagem & 89,9 & 90,5 \\
\hline Pastagem de degradação & 71,4 & 93 \\
\hline Pastagem degradada & 84,2 & 94,1 \\
\hline Solo exposto & 97,8 & 67,7 \\
\hline Kappa Statistic $(X 100)=93,9 \%$ & \\
\hline \multicolumn{2}{|l|}{ Kappa Variance $=0,000053$} \\
\hline
\end{tabular}

Tabela 2 - Acurácia referente à homogeneidade das amostras e a confiança da classificação da imagem de 2011.

\begin{tabular}{|l|c|c|}
\hline Acurácia & $\begin{array}{c}\text { Referência } \\
(\%)\end{array}$ & $\begin{array}{c}\text { Confiança } \\
(\%)\end{array}$ \\
\hline Cerrado florestado & 99,1 & 100 \\
\hline Mata de galeria & 98,8 & 98,8 \\
\hline Curso de água & 89,5 & 100 \\
\hline Silvicultura & 100 & 99,6 \\
\hline Pastagem & 100 & 99,3 \\
\hline Pastagem em degradação & 37,5 & 35,3 \\
\hline Pastagem degradada & 88,4 & 90,8 \\
\hline Solo exposto & 94,6 & 87,5 \\
\hline Nuvem & 71,4 & 71,4 \\
\hline \multicolumn{2}{|l|}{ Kappa Statistic $(X 100)=97,9 \%$} \\
\hline
\end{tabular}

Contudo, segundo a matriz de confusão, houve uma leve confusão entre as classes "Pastagem em degradação" e "Solo exposto" para o ano de 1984 e uma acentuada entre "Pastagem em degradação" e "Pastagem degradada" para o ano de 2011. Logo estas foram somadas para realizar as análises quantitativas dessas classes (Tabela 3). 
Tabela 3 - Dados quantitativos das classes usadas na classificação do uso do solo.

\begin{tabular}{|l|c|c|c|c|}
\cline { 2 - 5 } \multicolumn{1}{c|}{} & \multicolumn{2}{c|}{1984} & \multicolumn{2}{c|}{2011} \\
\cline { 2 - 5 } \multicolumn{1}{c|}{} & Hectares & $\%$ & Hectares & $\%$ \\
\hline Cerrado florestado & 5714,01 & 15,78 & 4710,15 & 13,01 \\
\hline Mata de galeria & 1059,48 & 2,93 & 985,41 & 2,72 \\
\hline Curso de água & 121,95 & 0,34 & 109,41 & 0,30 \\
\hline Pastvicultura & 0,00 & 0,00 & 1283,85 & 3,55 \\
\hline Pastagem & 20710,17 & 57,21 & 12626,28 & 34,88 \\
\hline Pastagem degradada & 6359,85 & 17,57 & 2216,16 & 6,12 \\
\hline Solo exposto & 992,34 & 2,74 & 12764,43 & 35,26 \\
\hline P. degradação + degradada + S. exposto & 1245,06 & 3,44 & 1487,97 & 4,11 \\
\hline Nuvem & 8597,25 & 23,75 & 16468,56 & 45,49 \\
\hline Total & 0,00 & 0,00 & 18,99 & 0,05 \\
\hline
\end{tabular}

O mapeamento temático ilustra a evolução temporal e espacial da paisagem na APA Guariroba (Figura 3). O avanço das áreas pastoris sobre as áreas de vegetação nativa foi majoritariamente anterior a 1984. Entre 1984 e 2011, a área passou por uma reconfiguração espacial, muitos fragmentos encontrados na APA hoje são de vegetação nativa secundária. Esses dados contrapõem os resultados de Dias (2005), o qual conclui que a área foi majoritariamente desmatada entre 1985 e 1995.

É notável que, na imagem de 1984, as áreas de pastagem em fase de degradação estão concentradas adjacentes aos cursos de água. Essa configuração pode indicar que a ocupação da área foi feita através do desmatamento da Mata ciliar. Apesar de não haver uma diferença significativa entre 1984 (1059,48 ha) e 2011 (985,41 ha), em 2011 há uma melhor distribuição da Mata Ciliar na APA Guariroba (Tabela 3).

Os cálculos das feições da paisagem indicam que em 1984 a matriz da paisagem era constituída de pastagem - 57,21\% da área total. Enquanto a área de vegetação nativa compunha $18,71 \%$ da área total da APA Guariroba.

As florestas nativas tiveram uma queda suave entre esses 27 anos - quase 3\% da área total da APA. Houve o surgimento de plantações de eucalipto em antigas áreas de pastagem - cerca de 3,5\%. A área de pastagem apresentou uma grande queda entre os anos de 1984 e 2011 - 22,33\% da área total da APA. Essa área foi substituída por pastagem em diferentes estágios de degradação e solo exposto - aumento de $21,74 \%$.

Pelas próprias características do solo, a cobertura vegetal é frágil, sendo facilitado o processo de erosão laminar e o consequente assoreamento de corpos de água e nascentes (CAMPO GRANDE, 2007). É importante destacar que a mata ciliar é muito importante no combate ao assoreamento de cursos de água, mas essa última barreira não pode ser a única, e sim fazer parte de um conjunto de técnicas específicas para cada área.

As três atividades econômicas recomendadas para a APA são encontradas na área hoje (Tabela 4). O índice de lucratividade média entre as atividades foi em torno de $15 \%$. O cultivo de eucalipto apresentou o maior percentual de lucratividade, porém um tempo de retorno e custo muito altos. A piscicultura apresentou lucratividade média e o menor tempo de retorno, porém o risco de investimento é o mais alto. A pecuária possui um baixo custo e risco de investimento, mas o menor índice de lucratividade, sendo a atividade mais comum na APA Guariroba. 


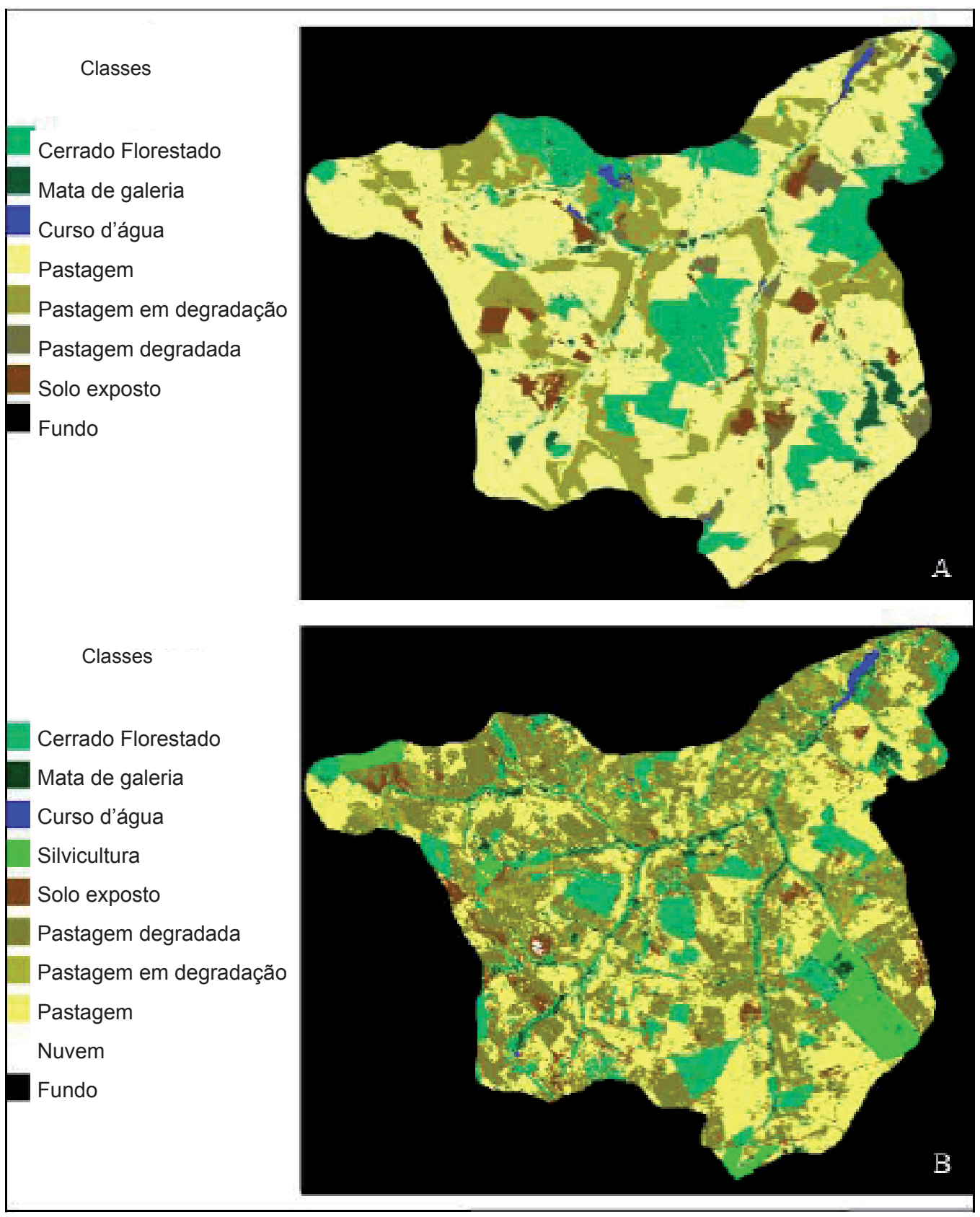

Figura 3 - Mapa temático construído a partir de imagem de 1984 (A) e 2011 (B).

Tabela 4 - Comparativo econômico e social de diferentes usos de solo recomendados para a APA Guariroba (1 ha de área útil).

\begin{tabular}{|l|c|c|c|}
\cline { 2 - 4 } \multicolumn{1}{c|}{} & Pecuária & Eucalipto & Psicultura \\
\hline Custo (R\$) & 800,00 & $8.347,50$ & $15.400,00$ \\
\hline Receita bruta & 1.3 & 18 & 33 \\
\hline Índice de lucratividade (\%) & 38,46 & 53,62 & 44,00 \\
\hline Lucratividade ano $^{-1}$ (R\$) & 250,00 & $1.378,93$ & $14.520,00$ \\
\hline Risco de investimento (comparativo) & + & ++ & +++ \\
\hline Tempo de retorno médio (anos) & 2 & 7 & 1 \\
\hline Empregos diretos (pessoas) & 1 & 12 & 3 \\
\hline Impacto ambiental (comparativo) & +++ & ++ & + \\
\hline
\end{tabular}


Entre todas as atividades, aquelas com maior impacto ambiental é a pecuária, seguida pela plantação de eucalipto. Apesar de a cultura de eucalipto ser um ambiente favorável para muitos organismos, este sofre alterações dramáticas na fase entre colheita e nova plantação (VACCA et al., 2000; DIAS JUNIOR et al., 2005).

O processo erosivo mostra-se intenso e extensivo em áreas de pecuária (PIMENTEL et al., 1995). Em áreas de eucalipto as taxas erosivas se assemelham àquelas encontradas em áreas de vegetação natural, contudo estudos relacionados aos estágios iniciais e de corte das florestas plantadas ainda são escassos (SILVA et al., 2011; SALGADO; MAGALHÃES JÚNIOR, 2006).

A engorda de gado de corte gera um emprego direto, enquanto a piscicultura gera três, e o eucalipto, cinco empregos. É importante salientar que na piscicultura há a necessidade de no mínimo uma pessoa qualificada para manejar a fase reprodutiva. No cultivo de eucalipto, são necessários operadores de máquinas e um especialista para fazer todo o planejamento das atividades. Essas duas atividades ainda apresentam um aumento significativo no número de empregos gerados no campo de acordo com o aumento da área de produção, o mesmo não ocorre na pecuária.

É muito importante lembrar que a Tabela 4 foi elaborada com base em uma área de um hectare, o que não condiz com a realidade de produção das áreas. Enquanto projetos de piscicultura têm menos do que 10 ha, projetos de eucaliptos e pecuária são compostos por mais de 100 ha.

Os valores obtidos no cálculo do valor de áreas de formações naturais da APA Guariroba são mostrados na tabela 5. A maior importância da Mata Ciliar e Áreas Úmidas aliadas às suas distribuições restritas tornam essas áreas mais valiosas, $\mathrm{R} \$ 10.555,86$ ha $^{-1}$ ano $^{-1}$ e R $\$ 6.378,90$ ha $^{-1}$ ano $^{-1}$ respectivamente. A oferta de quase cinco vezes mais Floresta e seu baixo valor de importância na produção de água fazem com que seu valor seja muito mais baixo, $\mathrm{R} \$ 5,23 \mathrm{ha}^{-1} \mathrm{ano}^{-1}$.

Tabela 5 - Valor monetário de diferentes formações da APA Guariroba com base na produção de água.

\begin{tabular}{|l|c|c|c|c|}
\cline { 2 - 5 } \multicolumn{1}{c|}{} & Importância & $\begin{array}{c}\text { Valor de área total } \\
\text { (RS/ano) }\end{array}$ & $\begin{array}{c}\mathbf{1 9 8 4} \\
\text { (RS/ha/ano) }\end{array}$ & $\begin{array}{c}\mathbf{2 0 1 1} \\
\text { (RS/ha/ano) }\end{array}$ \\
\hline Floresta & 0,26 & $24.635,71$ & 4,31 & 5,23 \\
\hline Áreas úmidas & 33,17 & $3.142 .947,56$ & $5.933,00$ & $6.378,90$ \\
\hline Mata ciliar & 54,89 & $5.200 .976,54$ & $9.817,98$ & $10.555,86$ \\
\hline Cursos de água & 11,69 & $1.107 .659,24$ & $9.082,90$ & $10.123,93$ \\
\hline Total & 100,00 & $9.475 .271,52$ & $1.374,14$ & $1.632,27$ \\
\hline
\end{tabular}

De acordo com os resultados das Tabelas 4 e 5, o valor das áreas de cursos de água e seus arredores compostos de vegetação natural possuem um valor de existência muito competitivo em comparação com qualquer atividade econômica desenvolvida na APA Guariroba. O abastecimento de água em Campo Grande ainda gera ao redor de 500 empregos diretos e conserva o meio ambiente.

Pagamentos por serviços ambientais são uma forma de incentivar proprietários a manter ou aumentar áreas conservadas. Essa estratégia mostra-se necessária, já que há a necessidade de suprir o custo de oportunidade. No caso de serviços ambientais, toda a população e governo são beneficiados.
É muito importante salientar que estudos específicos sobre valoração de ecossistemas sejam feitos para delimitar os valores mais corretos quanto possível. Os valores aqui gerados são apenas estimativas adaptadas de outros ecossistemas, com diferentes formações e dinâmicas ecológicas.

\section{Conclusão}

O software Multispec atendeu às necessidades deste estudo e é recomendado para outros trabalhos acadêmicos ou não acadêmicos. Sua manipulação é fácil, e sua interface, amigável, sendo de grande valia para operadores iniciantes. $\mathrm{O}$ método de análise 
econômico também foi muito satisfatório para alcançar os objetivos pré-estabelecidos.

A Área de Preservação Ambiental do Córrego Guariroba passou por uma grande reconfiguração da paisagem entre 1984 e 2011. A cobertura vegetal nativa apresentou queda e as áreas cultivadas de eucalipto aumentaram.

O dado que merece muita atenção é a enorme perda de áreas de pastagem, as quais evoluíram para solo em diferentes graus de degradação. A fim de evitar a degradação do solo, é necessário fazer uma boa adequação das atividades para as características físicas e biológicas das áreas.

Nos comparativos realizados neste trabalho está claro que os investimentos nas Áreas de Preservação Permanente conferem grandes benefícios socioeconômicos, além de serem de fundamental importância para a manutenção ambiental.

$\mathrm{O}$ aumento das áreas naturais faz com que os preços delas diminuam, melhoraram os serviços ambientais fornecidos (reduzem assoreamento e aumentam a vazão). $\mathrm{O}$ equilíbrio entre as atividades econômicas e serviços ambientais são de fundamental importância para a sustentabilidade da área, e assim garantir benefícios econômicos, sociais e ambientais.

\section{Referências}

BOYD, J.; BANZHAF, S. What are ecosystem services? the need for standardized environmental accounting units. Washington, DC: Resources for the Future: 2006. $29 \mathrm{p}$.

CAMPO GRANDE, P. M. Plano de Manejo da Área de Proteção Ambiental dos Mananciais do Córrego Guariro$b a$ - APA do Guariroba. Campo Grande, MS: PMCG, 2007. 156 p.

. Decreto Municipal n. 11.691, de 09 de dezembro de 2011. Diário Oficial, Campo Grande, MS, ano XIV, n. 3.414, p. 1-2, 2011.

CHIARAVALLOTI, R. M.; VALLADARES-PADUA, C. Escolhas sustentáveis. São Paulo: Editora Urbana, 2011. 168p. Disponível em: <http:/ / books.google.com.br/bo oks?id=XTibbt7ysD8C\&printsec $=$ frontcover\&dq=inaut hor:\%22RAFAEL+MORAIS+CHIARAVALLOTI\%22\& $\mathrm{hl}=$ pt-BR\&sa $=X \&$ ei $=$ HPNgU7P7Ia62sATloIDwBA\&ve $\mathrm{d}=0 \mathrm{CDEQ6} w$ EwAA\# $\mathrm{v}=$ onepage\& $\mathrm{q} \& \mathrm{f}=$ false $>$.

COSTANZA, R. et al. The value of the world's ecosystem services and natural capital. Ecological Economics, v. 25, n. 1, p. 3-16, apr. 1997.

The Value of New Jersey's Ecosystem Services and Natural Capital. G. I. F. E. Burlington, VT: University of Vermont, 2006. 167p.
DE GROOT, R. S.; WILSON, M. A.; BOUMANS, R. M. J. A typology for the classification, description and valuation of ecosystem functions, goods and services. Ecological Economics, v. 41, n. 3, p. 393-408, jun. 2002. Disponível em: <http://www.journals.elsevier.com/ ecological-economics $/>$.

DELALIBERA, H. C. et al. Alocação de reserva legal em propriedades rurais: do cartesiano ao holístico. Revista Brasileira de Engenharia Agrícola e Ambiental, Campina Grande, v. 12, p. 286-292, 2008. Disponível em: <http:/ / www.scielo.br/scielo.php?script=sci_ arttext\&pid=S1415-43662008000300010\&nrm=iso $>$.

DIAS, E. F. Georreferenciamento no estudo do uso e ocupação do solo na microbacia do Guariroba no município de Campo Grande (MS). 2005. 81f. Monografia (Especialização em Georreferenciamento de Imóveis Rurais) - Universidade Católica Dom Bosco, Campo Grande, MS, 2005.

DIAS JUNIOR, M. D. S. et al. Traffic effects on the soil preconsolidation pressure due to eucalyptus harvest operations. Scientia Agricola, Piracicaba, SP, v. 62, n. 3, p. 248-255, 2005.

GOODLAND, R. The concept of environmental sustainability. Annual Review of Ecology and Systematics, Palo Alto, USA, v. 26, p. 1-24, Nov. 1995.

HESS, G. et al. Engenharia Economica. São Paulo: Difusão Editorial, 1980. 165 p.

IBGE. PIB cresce $0,6 \%$ em relação ao $2^{\circ}$ tri de 2012 e chega a R\$1,10 trilhão, 2012. Disponível em: <http://www. ibge.gov.br/home/presidencia/noticias/noticia_visualiza.php?id_noticia $=2272 \& i d \_p a g i n a=1 \&$ titulo=PIBcresce-0,6\%-em-relacao-ao-2\% BA-tri-de-2012-e-chegaa-R\$-1,10-trilhao>. Acesso em: 2 jan. 2012.

LU, D. S. et al. Comparison of land-cover classification methods in the Brazilian Amazon Basin. Photogrammetric Engineering and Remote Sensing, v. 70, n. 6, p. 723-731, jun. 2004. Disponível em: <http://www.indiana.edu/ act/ files/curriculum_vitae/dlu_webCV/June_PERS_2004. pdf $>$.

MARTINEZ, L. M. et al. Effects of land use change on biodiversity and ecosystem services in tropical montane cloud forests of Mexico. Forest Ecology and Management, v. 258, n. 9, p. 1856-1863, oct. 2009.

METZGER, J. P. et al. Brazilian law: full speed in reverse? Science, v. 329, n. 5989, p. 276-277, jul. 2010.

MORAES, A. S. Pecuária e conservação do pantanal: análise econômica de alternativas sustentáveis - o dilema entre benefícios privados e sociais. 2008. 265f. Tese (Doutorado em Economia) - Universidade Federal de Pernambuco, Recife, PE, 2008.

NAZARENO, A. G. Call to veto Brazil's forest-code revisions. Nature, v. 481, n. 7379, p. 29-29, jan. 2012.

PARANHOS FILHO, A. C.; LASTORIA, G.; TORRES, T. G. Sensoriamento remoto ambiental aplicado. Campo Grande, MS: UFMS, 2008. 198p.

PIMENTEL, D. et al. Environmental and Economic Costs of Soil Erosion and Conservation Benefits. Science, v. 267, n. 5201, p. 1117-1123, 1995. Disponível em: <http:// www.sciencemag.org/content/267/5201/1117.abstract>. 
SALGADO, A. A. R.; MAGALHÃES JÚNIOR, A. P. Impactos da silvicultura de eucalipto no aumento das taxas de turbidez das águas fluviais: o caso de mananciais de abastecimento público de Caeté/MG. Geografias, Belo Horizonte, 01, p. 47-57, 2006.

SBPC, S. B. P. O. P. D. C. O Código Florestal e a Ciência: contribuição para o diálogo. São Paulo: Academia Brasileira de Ciências, 2011. 124p.

SILVA, M. A. da et al. Management systems in the eucalyptus forest plantations and the soil and water losses in Vale do Rio Doce, MG state. Ciencia Florestal, Santa Maria, v. 21, n. 4, p. 765-776, Oct-Dec 2011.

SPAROVEK, G. et al. A revisão do Código Florestal brasileiro. Novos Estudos - CEBRAP, São Paulo, n. 98, p. 111-135, 2011. Disponível em: <http://www.
scielo.br/scielo.php?script=sci_arttext\&pid=S010133002011000100007\&nrm=iso>.

STOKSTAD, E. Controversial Changes to Forest Law Pass Brazilian Senate. Science Insider: Science Magazine Online, dez. 2011. Disponível em : <http:/ / news. sciencemag.org/scienceinsider/2011/12/controversialchanges-to-forest.html>

TOLLEFSON, J. Brazil revisits forest code. Nature, v. 476, n. 7360, p. 259-260, aug. 2011. Disponível em: <http:/ / www.nature.com/news/2011/110817/full/476259a. html>.

VACCA, A. et al. Measurement of runoff and soil erosion in three areas under different land use in Sardinia (Italy). Catena, v. 40, n. 1, p. 69-92, jun. 2000 